ICOSITER 2018 Proceeding

Journal of Science and Applicative Technology

\title{
Simulation of Electric Field Distribution on Meniscus of Electrospray with Zinc Oxide Material
}

\author{
Andam Deatama Refino ${ }^{1 * \#}$, Hadi Teguh Yudistira ${ }^{2 *}$, Denny Hidayat Tri Nugroho ${ }^{3}$, Deska \\ Lismawenning P. ${ }^{4}$ \\ ${ }^{1}$ Engineering Physics Program, Institut Teknologi Sumatera (ITERA), Lampung Selatan, Lampung \\ ${ }^{2}$ Mechanical Engineering Program, Institut Teknologi Sumatera (ITERA), Lampung Selatan, Lampung \\ ${ }^{3}$ Electrical Engineering Program, Institut Teknologi Sumatera (ITERA), Lampung Selatan, Lampung \\ ${ }^{4}$ Physics Program, Institut Teknologi Sumatera (ITERA), Lampung Selatan, Lampung \\ *Equal contribution \\ \#Corresponding author: andam.refino@tf.itera.ac.id
}

\begin{abstract}
Electrospray system had attracted attention of many researchers. It is due to easy to yield uniform thin film and possible for thin film mass production. The important parameters of electrospray process for getting uniform thin film are electric field distribution, surface substrate treatment and solvent properties. In this work, we observed electric field distribution on meniscus. Numerical work has carried out on this work. The material on meniscus used zinc oxide liquid properties. Voltage and walking distance between nozzle and substrate are the most important parameter to adjust electric field distribution. The decreasing walking distance with constant voltage yields increasing electric field distribution on meniscus. On vice versa, the increasing walking distance yields decreasing electric field distribution on meniscus. Increasing and decreasing voltage yields increasing and decreasing electric field distribution on meniscus, respectively.
\end{abstract}

Key words: electrospray, electric field, voltage, meniscus.

\section{Introduction}

Currently, energy issue is one of the main concern of the society. As the energy demand increases, sufficient energy source is required to meet these energy needs. One of the efforts to answer this issue is by diversification of energy sources whilst present supply is highly dependent on fossil sources. The use of renewable energy is an effort to bring diversification of energy into reality. One of the renewable energy that can be utilized is sunlight. Solar cell is a technology that could convert sunlight into electrical energy. At present, the development of solar cells technology is remarkably fast, starting with the first generation solar cells to fourth generation solar cells[1]. The performance characteristics of each generation can be summarized as follows: high cost and high efficiency (first generation, bulk silicon), low cost and low efficiency (second generation, thin film a-Si: H), low cost and high efficiency (third generation, organic photovoltaic), low cost and flexible (fourth generation, organic photovoltaic with plasmonic nano particles). Beyond the second generation of solar cells has started using thin films. Several methods are used today to make thin films such as chemical vapor deposition[2], atomic layer deposition[3], electron beam evaporators [4] and sputtering[5]. Most of the thin film making methods costs a lot in terms of equipment as well as the maintenance of the machines used. Some efforts to reduce 
the cost of solar cells by maintaining their good performance such as material choice and engineer the manufacturing and fabrication techniques. Electrohydrodynamic phenomenon has been attracted for new technique on microfabrication[6-8]. It can reduce production cost and possible for mass production. In this research, fabrication techniques are studied using electrospray based on electrohydrodynamic phenomenon method due to its relatively low cost and its high throughput that open the possibility for mass production processes[9]. Simulation was performed to find the optimal parameters that can be used at the next stage of the experiment to obtain a stable electrospray process.

\section{Method}

Data collection was carried out using numerical simulation. In this case, the software that was used is CST microwave studio. The results of this numerical simulation was obtained as an electrostatic phenomenon information in the form of electric field, which can then be used further for the determination of the area where the electrospray phenomenon was performed.

\section{Result and Discussion}

In current work, numerical simulation was carried out to determine the condition of the part that used as a voltage-producing component. Properties that resemble an ethanol-based solution of zinc oxide was used in this simulation.
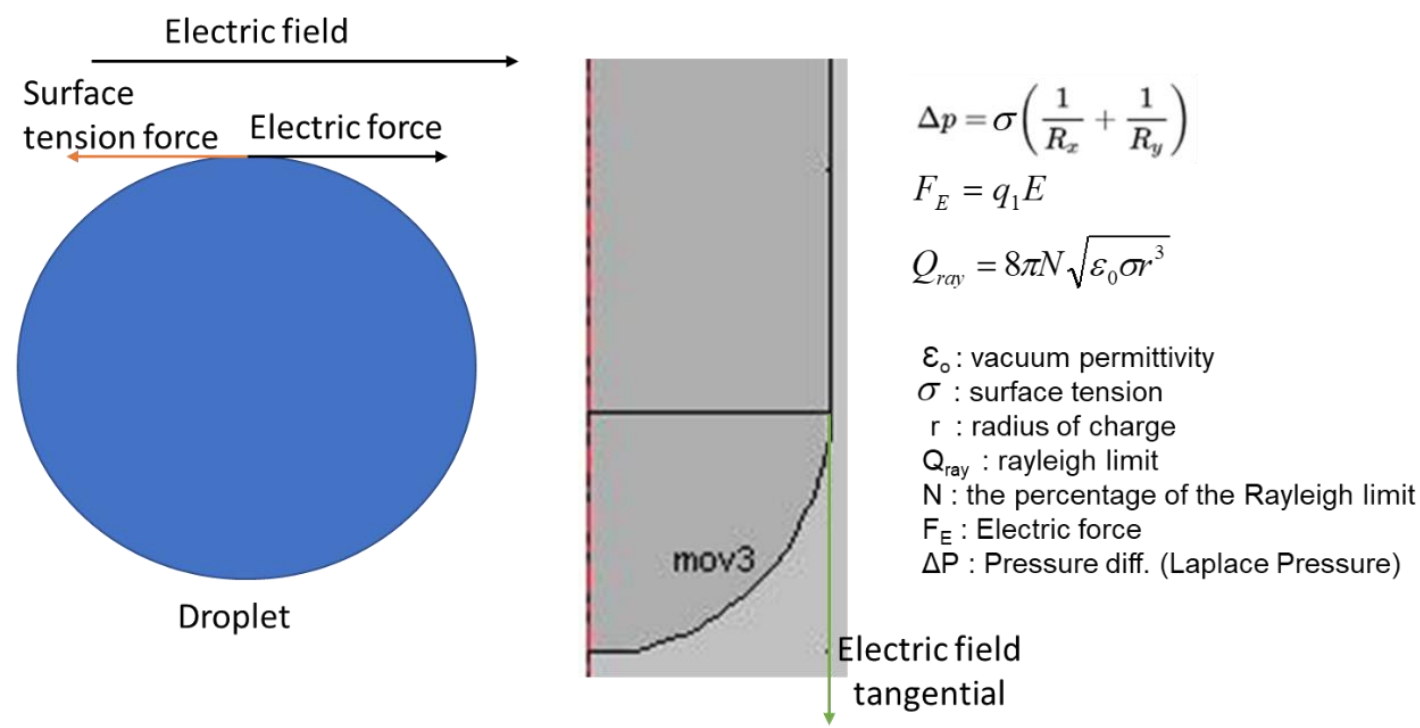

Figure 1 Mathematical model used in the simulation

Figure 1 provides a summary of mathematical model used in the simulation. Laplace pressure equation and electric force equation were used to investigate electrospray stable areas. The results of electric field distribution in tangential direction could be seen in Figure 2. 
ICOSITER 2018 Proceeding

Journal of Science and Applicative Technology

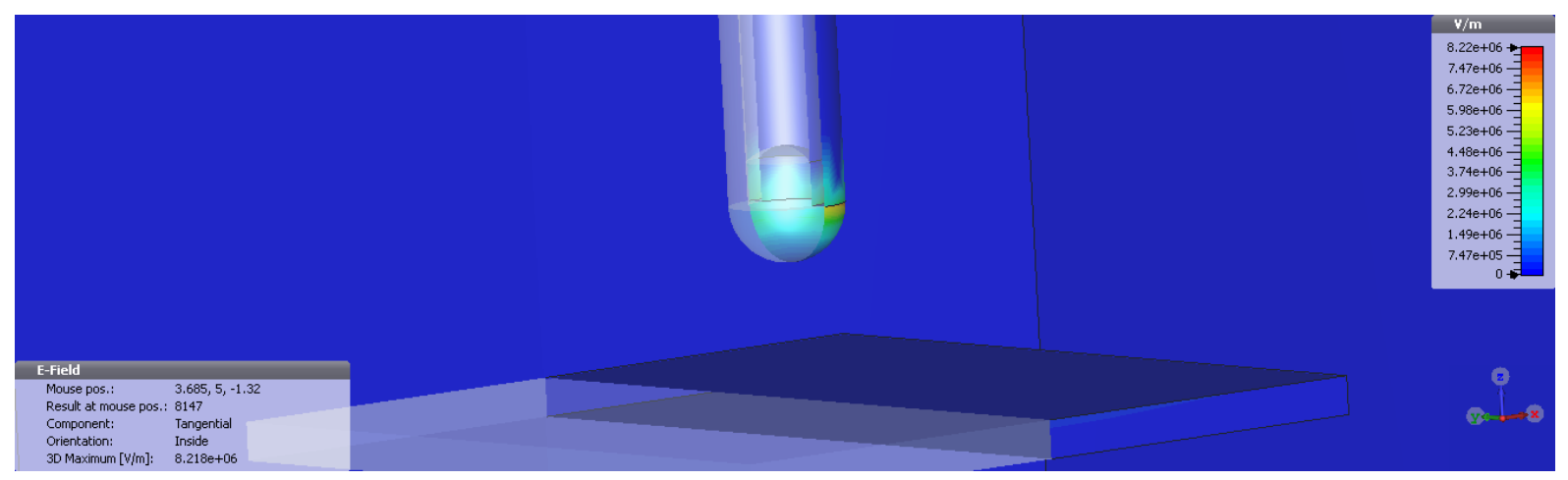

Figure 2 Distribution of electric field in tangential direction along the surface of solution meniscus

From this electric field distribution data, one could predict jetting stability area by taking $\mathrm{N}$ value between $0.1-0.25$ which is the relative presentation value of coulomb fission had not yet occurred.

Surface force was estimated at $4.03 \times 10^{-5} \mathrm{~N}$. In this condition $\mathrm{N}=0.1$ as represented in Figure 3(a), for walking distance (WD) between $0.5-1 \mathrm{~mm}$ and voltage up to $2 \mathrm{KV}$ still results in a stable jetting condition because the tangential direction of the electric force is still far below the surface tension force. From Figure 3(b) it could be seen that when the value of $\mathrm{N}=0.15$, system still exhibits a stable area for condition up to $2 \mathrm{KV}$ voltage. At condition $\mathrm{N}=0.2$ (Figure 3(c)), it could be seen that the stable area was reached at the voltage around $1.6 \mathrm{KV}$ for WD $0.5 \mathrm{~mm}$ and $0.75 \mathrm{~mm}$. As for the WD $1 \mathrm{~mm}$, the stable area was reached when the voltage was around $1.8 \mathrm{KV}$. Electric force for WD 0.5 and $0.75 \mathrm{~mm}$ did not show significant difference. Finally, in condition $\mathrm{N}=0.25$ (Figure 3(d)), stable area was begun to decrease. For the case of WD $0.5 \mathrm{~mm}-0.75 \mathrm{~mm}$ the stable area was reached at $1.3 \mathrm{KV}$ whilst for WD $=1 \mathrm{~mm}$ was reached up to a voltage of $1.4 \mathrm{KV}$.

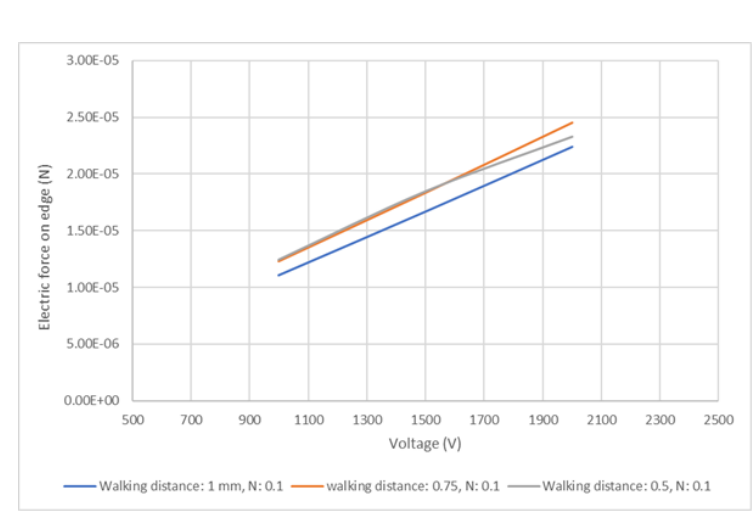

(a)

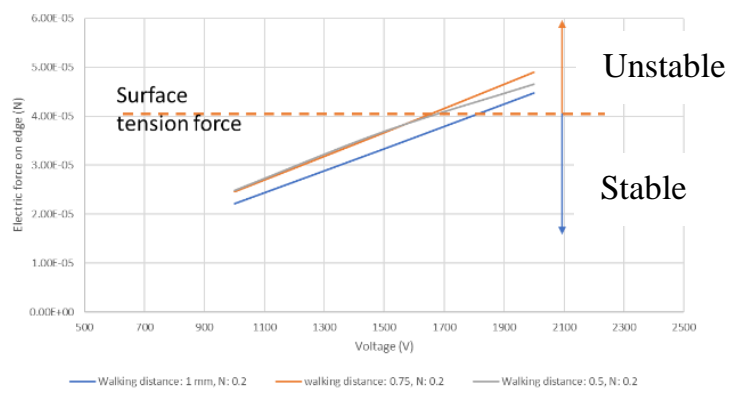

(c)

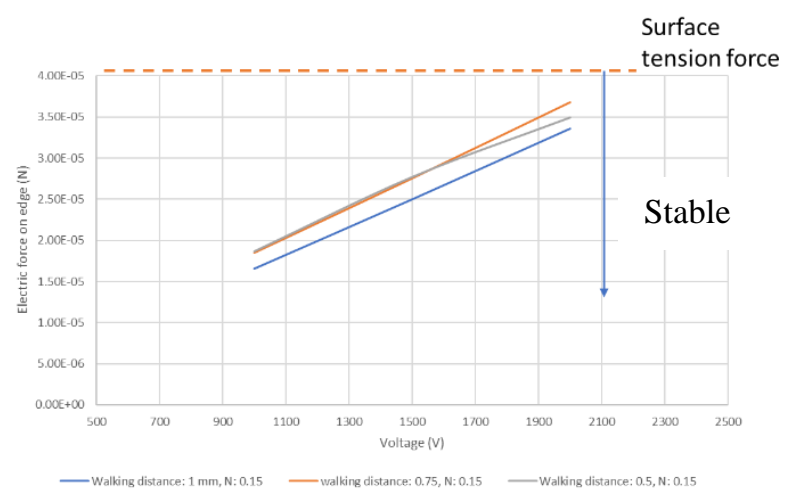

(b)

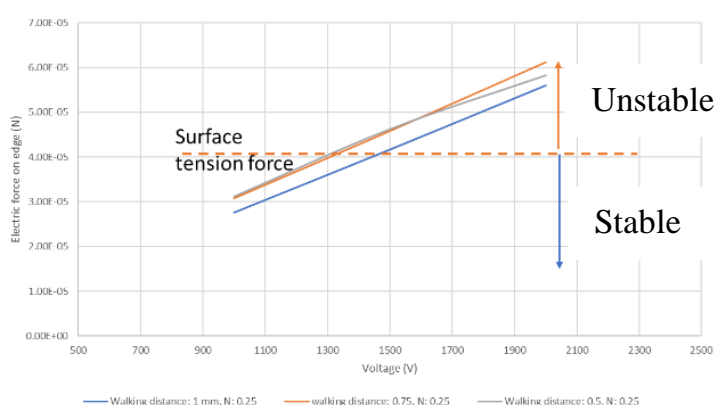

(d)

Figure 3 Electric force on the tip of the nozzle at (a) $N=0.1$, (b) $N=0.15$, (c) $N=0.2$, (d) $N=0.25$. 
ICOSITER 2018 Proceeding

Journal of Science and Applicative Technology

\section{Conclusion}

The stability of the jetting is determined by the property of the applied solution. Electric force at the end of the nozzle was carefully controlled since if the jetting occurs right at the tip of the nozzle, then the electrospray results become unstable. Based on the results of simulation, it was indicated that if the solvent used has an ethanol basis and the nozzle diameter is relatively small, the maximum operating voltage used was around 1.4 KV to maintain its stability. Moreover, walking distance (WD) that is safe to use for a $150 \mu \mathrm{m}$ diameter nozzle is $1 \mathrm{~mm}$. This was showed by the results of the electric force when WD is $0.75 \mathrm{~mm}$ and $0.5 \mathrm{~mm}$, no significant electric force changes occurs.

\section{Acknowledgement}

This work is supported by Hibah Mandiri grant from Institut Teknologi Sumatera.

\section{Reference}

[1] K. I. Jayawardena, et al., "'Inorganics-in-Organics': recent developments and outlook for 4G polymer solar cells," Nanoscale, vol. 5, pp. 8411-8427, 2013.

[2] Q. Zheng, et al., "Thermal conductivity of graphite thin films grown by low temperature chemical vapor deposition on $\mathrm{Ni}$ (111)," Advanced Materials Interfaces, vol. 3, 2016.

[3] Y. S. Lee, et al., "Atomic Layer Deposited Aluminum Oxide for Interface Passivation of Cu2ZnSn (S, Se) 4 Thin-Film Solar Cells," Advanced Energy Materials, vol. 6, 2016.

[4] S. Mathuri, et al., "Effect of substrate temperature on the structural and optical properties of $\mathrm{CdSe}$ thin film deposited by electron beam evaporation technique," Journal of Materials Science: Materials in Electronics, vol. 27, pp. 7582-7588, 2016.

[5] V. A. Sugiawati, et al., "Porous NASICON-Type Li3Fe2 (PO4) 3 Thin Film Deposited by RF Sputtering as Cathode Material for Li-Ion Microbatteries," Nanoscale research letters, vol. 11, p. 365, 2016.

[6] H. T. Yudistira, "Fabrication of Tera-hertz Metamaterial using Drop-on-demand Electrohydrodynamic (EHD) Jet Printing " Doctoral Doctoral Thesis, Department of Mechanical Engineering, Sungkyunkwan University, Suwon, 2014.

[7] H. T. Yudistira, et al., "Flight behavior of charged droplets in electrohydrodynamic inkjet printing," Applied Physics Letters, vol. 96, pp. 023503-023503-3, 2010.

[8] H. T. Yudistira, et al., "Retreat behavior of a charged droplet for electrohydrodynamic inkjet printing," Applied Physics Letters, vol. 98, pp. 083501-083501-3, 2011.

[9] S. C. Hong, et al., "Precise Morphology Control and Continuous Fabrication of Perovskite Solar Cells Using Droplet-Controllable Electrospray Coating System," ACS Applied Materials \& Interfaces, vol. 9, pp. 7879-7884, 2017. 